\title{
OPTIMIZATION OF FLY ASH CONTENT IN DIFFERENT GRADES OF MAGNETIC WATER CONCRETE
}

\author{
A.Venkat Reddy ${ }^{1}$, Divya Kolasani ${ }^{2}$ \\ ${ }^{1}$ Assistant Professor, Department of Civil Engineering, CVR College of Engineering \\ ${ }^{2}$ Assistant Professor, Department of Civil Engineering, CVR College of Engineering
}

\begin{abstract}
This paper presents that when water is magnetised, it exhibits structural changes which increases the specific surface area of water. When this magnetised water is used in concrete instead of normal water, it is found that the compressive strength increases considerably. The additional strength attained by the use of magnetised water is used to address the need for reducing cement usage in concrete. In this attempt to reduce the usage of cement, fly ash which has immense potential to be used in construction industry, can be used to replace cement in concrete to a considerable extent. Based on the experimental results obtained by conducting tests on workability and compressive strength, optimum fly ash content for various grades of concrete are achieved.
\end{abstract}

Keywords: Magnetic water, Magnetic water concrete, Fly ash, Normal water concrete, Optimization, Compressive Strength.

\section{INTRODUCTION}

Concrete is the second most consumed substance on Earth after water and it accounts for around 5\% of total carbon dioxide emissions. This alarming level of emissions called for an instant focus to substitute cement by other materials. Fly ash is a byproduct produced in thermal plants. The country's dependence on coal for power generation is increasing and so the production of fly ash will also be more. This largely available unused material can be used as a partial replacement for cement in concrete. By this the environmental concerns of both cement production and fly ash can be addressed.

According to a previous study, the usage of magnetic water improved the strength of concrete by almost $50 \%$. This additional strength attained by the use of magnetised water can be used to address the need of reducing the usage of cement in concrete. In this attempt, fly ash, which exhibits cementitious properties is used to replace cement in concrete to a considerable extent.

\section{RESEARCH METHODOLOGY}

Concrete is universal construction material, cement, water and aggregates are its constituents. $80 \%$ of the volume of concrete is composed of aggregates and these aggregates are bound together by C-S-H gel. The C-S-H gel is the product of chemical reaction between water and cement known as hydration of cement. During the process of hydration, some part of cement grain remains unhydrated. More is the C-S-H gel formed, greater will be the compressive strength of concrete obtained. Evidently, quantity of $\mathrm{C}-\mathrm{S}-\mathrm{H}$ gel can be increased by increasing the cement content in the mix. But, this results in increased usage of cement which is uneconomical. Therefore a lot of research is done to increase the quantity of C-S-H gel without actually increasing the cement content. This lead to greater insights on the hydration of cement and it is found that the extent of hydration can be increased by reducing the particle size of cement particles, i.e., increasing the surface area. Hence different grades of cement came up such as 33 grade, 43 grade and 53 grade. The particle size of cement in 53 grade is less than that of 43 and 33 grade, which resulted in increased formation of C-S-H gel, thereby improving overall strength of concrete or cement mortar. Aggregates occupy a major volume of concrete and generally $20 \mathrm{~mm}$ and $12 \mathrm{~mm}$ aggregates are used in construction. Increase in size of coarse aggregate from $20 \mathrm{~mm}$ results in reduced thickness of cement paste around the aggregates and results in segregation of cement paste. Decrease in size from $12 \mathrm{~mm}$ results in an increase in demand for cement content to bind the same quantity of aggregates which conflicts with our interest. Increase in the use of fine aggregate by replacing coarse aggregate increases the strength, but it demands more cement content. Therefore aggregates are not of much interest in increasing the strength by using the same quantity of materials in the same proportions.

Water has long been neglected in research studies related to the construction industry. Various standards have been established for the quality of water to be used in construction. Most of them stipulate that potable water is fit to be used in construction. Unlike coarse aggregates, water is not inert. Water is very important for the hydration of cement. When the specific surface area of cement is increased, it improves the extent of hydration. Therefore, attempts have been made to increase the specific surface area of water and the effects of increased surface area are studied on the workability and compressive strength of concrete. Magnetising the water is found to be helpful in increasing the specific surface area of water, thereby increasing the rate of hydration. 


\section{EXPERIMENTAL PROCEDURE}

\subsection{Materials}

\subsubsection{Normal Water and Magnetic Water}

Water is the least expensive but most important component of concrete. The water, which is used for making concrete, should be clean and free from harmful impurities such as oil, alkali, acid, etc. In general the water, which is fit for drinking, should be used for making concrete.

Throughout the investigation, water is magnetised by placing 1 liter glass beaker over a magnet of strength 985 Gauss, for a period of 24 hours. As magnetic flux passes through the water the specific surface area of water molecule changes and this water is used in the preparation of concrete.

Various physical tests have been conducted on Magnetic water and normal water. The results obtained are tabulated below:

Table 1 Physical tests conducted on NW and MW

\begin{tabular}{|c|c|c|c|c|c|}
\hline Property & pH & Turbidity & Allkalinity & Chlonides & Hardness \\
\hline Normal & 7.2 & 7 & 20 & 28 & 112 \\
\hline Magnetic & 7.9 & 7 & 20 & 28 & 84 \\
\hline
\end{tabular}

Table 2 Normal consistency of cement for different waters

\begin{tabular}{|l|c|}
\hline Type of water & Normal Consistency (\%) \\
\hline Normal water & 30 \\
\hline Magnetic water & 33 \\
\hline
\end{tabular}

\subsubsection{Aggregates}

Coarse aggregate (CA) used in the investigation are of two sizes viz. $20 \mathrm{~mm}$ and $12 \mathrm{~mm}$. The crushed coarse aggregate is obtained from the local crushing plants. Fine aggregate (FA) is sourced from a local supplier viz. river sand.

The physical properties of aggregates were tested in accordance with IS: 2386 and the results are tabulated below:

Table 3: Physical properties of CA and FA used in the mix

\begin{tabular}{|l|c|c|c|}
\hline Properties & $\begin{array}{l}\text { Coarse Aggregate } \\
(20 \mathrm{~mm})\end{array}$ & $\begin{array}{l}\text { Coarse Aggregate } \\
(12 \mathrm{~mm})\end{array}$ & Fine Aggregate \\
\hline Fineness modulus & 7.228 & 5.314 & 2.88 \\
\hline Specific gravity & 2.6 & 2.58 & 2.6 \\
\hline $\begin{array}{l}\text { Bulk density in loose } \\
\text { state }\end{array}$ & $1361 \mathrm{~kg} / \mathrm{m} 3$ & $1332 \mathrm{~kg} / \mathrm{m} 3$ & $1550 \mathrm{~kg} / \mathrm{m} 3$ \\
\hline
\end{tabular}

\subsubsection{Cement}

Locally available 53 grade Ordinary Portland Cement (OPC) of Ultratech brand is used in the present investigation for all concrete mixes. The cement procured is tested for physical and chemical requirements in accordance with IS 122691987 and the results are shown in Table 4.

Table 4: Physical properties of Cement used in the mix

\begin{tabular}{|c|c|}
\hline Properties & Test Result \\
\hline Normal consiste0ncy & $30 \%$ \\
\hline Specific gravity & 3.02 \\
\hline Initial setting time (minutes) & $55 \mathrm{~min}$ \\
\hline Final setting time (minutes) & $560 \mathrm{~min}$ \\
\hline Fineness & $3 \%$ \\
\hline Soundness (Le-chatelier's method) & $2 \mathrm{~mm}$ \\
\hline Compressive strength (28 days) & $54.7 \mathrm{~N} / \mathrm{mm} 2$ \\
\hline
\end{tabular}

\subsubsection{Fly Ash}

For the present study fly ash is incurred from National Thermal Power Corporation Limited (NTPC), Ramagundam. The fly ash used conformed to the requirements of IS: 3812 Part 1 and also ASTM C-618 type F.

Table 5: Chemical composition of fly ash used

\begin{tabular}{|l|c|c|c|}
\hline \multirow{2}{*}{$\begin{array}{l}\text { Chemical composition } \\
\text { of fly ash }\end{array}$} & \multirow{2}{*}{ Test Value } & \multicolumn{2}{|c|}{ Acceptable Value } \\
\cline { 3 - 4 } & & IS 3812-2003 Part 1 & ASTM C-618 Type -F \\
\hline $\mathrm{SiO} 2$ & 58.74 & Min. 35 & - \\
\hline $\mathrm{SiO} 2+\mathrm{Al2O}+\mathrm{Fe} 2 \mathrm{O} 3$ & 93.77 & Min. 70.0 & Min. 70.0 \\
\hline $\mathrm{MgO}$ & 0.48 & Max. 5.0 & - \\
\hline $\mathrm{SO} 3$ & 1.8 & Max. 3.0 & Max. 5.0 \\
\hline Na2O & 0.16 & Max. 1.5 & - \\
\hline Loss of Ignition (\%) & 0.59 & Max. 5.0 & Max. 6.0 \\
\hline Moisture Content (\%) & 0.051 & - & Max. 3.0 \\
\hline
\end{tabular}


Table 6: Physical Properties of Fly ash

\begin{tabular}{|c|c|c|c|}
\hline \multirow{2}{*}{ Description Test } & \multirow{2}{*}{ Test Value } & \multicolumn{2}{|l|}{ Acceptable Value } \\
\hline & & IS 3812-2003 Part 1 & ASTM C-618 Type -F \\
\hline Setting Time (min) Initial & 130 & - & - \\
\hline Setting Time (min) final & 290 & - & - \\
\hline Retained on 45 micron (\%) & 2.77 & Max.34.0 & Max.34.0 \\
\hline $\begin{array}{lll}\text { Specific } & \text { Surface } & \text { Area } \\
(\mathrm{m} 2 / \mathrm{kg}) & & \\
\end{array}$ & 328 & Min. 320 & - \\
\hline $\begin{array}{l}\text { Soundness(Le-chatelier's } \\
\text { method) }\end{array}$ & $0.15 \mathrm{~mm}$ & - & - \\
\hline Soundness (Autoclave) (\%) & 0.027 & Max. 0.8 & Max. 0.8 \\
\hline Water requirement & 96 & - & Max. 105 \\
\hline Compressive Strength & & & \\
\hline a) 7 Days & 158.1 & $\begin{array}{l}\text { strength of corresponding } \\
\text { plain cement mortar cubes }\end{array}$ & - \\
\hline b) 28 Days & 160.9 & & Min. 75 \\
\hline
\end{tabular}

\subsection{Mix Compositions}

The material quantities obtained as per mix design method, (i.e., IS: 10262-2009) arrived in trial mix are given in Table 7. The quantities of materials required per one cubic meter of concrete.

Table 7: Trial mix proportions for $1 \mathrm{~m} 3$ of concrete

\begin{tabular}{|r|c|r|r|r|r|}
\hline \multirow{2}{*}{ Grade } & \multicolumn{3}{|c|}{ Materials (Kg/m3) } & \multirow{2}{*}{ Water/cement } \\
\cline { 2 - 5 } & Cement & F.A. & C.A. & Wate & \\
\hline M 20 & 310 & 718 & 1167 & 170.5 & 0.55 \\
\hline M 30 & 355 & 704 & 1144 & 170.5 & 0.48 \\
\hline M 40 & 371 & 699 & 1136 & 170.5 & 0.46 \\
\hline
\end{tabular}

\section{PREPARATION OF TEST SPECIMENS}

For the present investigation, machine mixing is adopted and while mixing the various ingredients of concrete namely, cement, fly ash, fine aggregate, coarse aggregate and water are weighed according to the designed mix proportions with respect to the required number of cube specimens of $150 \mathrm{~mm}$ size. The required quantity of cement and aggregates are thoroughly blended after being poured into the pan mixer. The materials are thoroughly mixed in their dry condition before water is added. Then calculated amount of water is gradually added and wet mixing is done until a mixture of uniform color is achieved. The mixer used during the entire study, run at a speed of 20 to 25 revolutions per minute. The workability of the fresh concrete is measured by means of conventional slump test.
For casting the test specimens, standard size of $150 \times 150 \times$ $150 \mathrm{~mm}$ cubes made with cast iron, metal moulds are used to cast the test specimens. The moulds have been cleaned to remove the dust particles from the mould and mineral oil is applied on all sides of the mould, before concrete is poured into the mould. Thoroughly mixed concrete is filled into the mould and vibrated by a pin vibrator. Excess concrete was removed using trowel and top surface is finished, level and smooth.

After casting, the moulded specimens are stored in the laboratory in moist air and at room temperature for 24 hours. During this time, care is taken that moulds are placed on a surface which is free from vibrations. After 24 hours, the specimens are removed/ demoulded from the moulds and immediately submerged in clean, fresh water of curing tank. Cubes are allowed for curing in the curing tank until the day of testing. On the day of testing the cubes are removed from curing tank and are allowed to dry, before the cubes are tested for compressive strength. Cubes are tested for compressive strength on $7,14,21,28,60$ and 90 days respectively.

During this research work, the compression testing machine of $3000 \mathrm{kN}$ is employed to determine the compressive strength of cube specimens. After the required period of curing, specimens are removed from the curing tank just before testing. They are cleaned and dried to make them surface dry. The cube specimen is placed on the lower platen in such a manner that the load is applied centrally on opposite side of the cube and right angles to that has cast. The rate of load is applied is equal to $2 \mathrm{KN} / \mathrm{sec}$. The oil pressure valve is closed then the compression testing machine is switched on. The top plate of the compression testing machine is brought into contact with the surface of the cube specimen, and then the clutch is operated with suitable rate of loading, the load improvements are displayed in digital screen system. The load was applied until the resistance of the specimen to the increasing load broke down and no higher load is sustained, then the digital screen reading starts moving back, at this stage the pressure valve of the compression testing machine is released then automatically the ultimate load is displayed in the digital screen, and the platens are also loosened, now crushed specimen is removed from compression testing machine, and the maximum load applied to the specimen is noted down. The same procedure is repeated for testing all other test specimens. The compressive strength of the specimen was calculated by dividing the maximum load applied on the specimen during the test by the cross sectional area of the cube, for this purpose three specimens of same batch are tested and the average of three values is reported.

The compression test on hardened MWC with different durations of magnetic field exposure is performed on a 3000 $\mathrm{KN}$ capacity CTM in accordance to the relevant Indian standards. 


\section{RESULTS}

Immediately after mix is prepared, slump test is done for to assess workability. Slump test is conducted for all the mixes used in this study. The results obtained (in $\mathrm{mm}$ ) for various grades of concrete are tabulated below.

Table 8: Workability (in cm) of N.W.C and M.W.C for different $\%$ fly ash replacements

\begin{tabular}{|r|c|c|c|c|}
\hline GRADE & \% Fly ash & $0 \%$ & $30 \%$ & $40 \%$ \\
\hline \multirow{2}{*}{ M20 } & N.W.C. & 50 & 60 & 65 \\
\cline { 2 - 5 } & M.W.C & 55 & 70 & 75 \\
\hline \multirow{2}{*}{ M30 } & N.W.C. & 65 & 75 & 80 \\
\cline { 2 - 5 } & M.W.C & 70 & 80 & 85 \\
\hline \multirow{3}{*}{ M40 } & N.W.C. & 60 & 70 & 75 \\
\cline { 2 - 5 } & & & & 80 \\
\hline
\end{tabular}

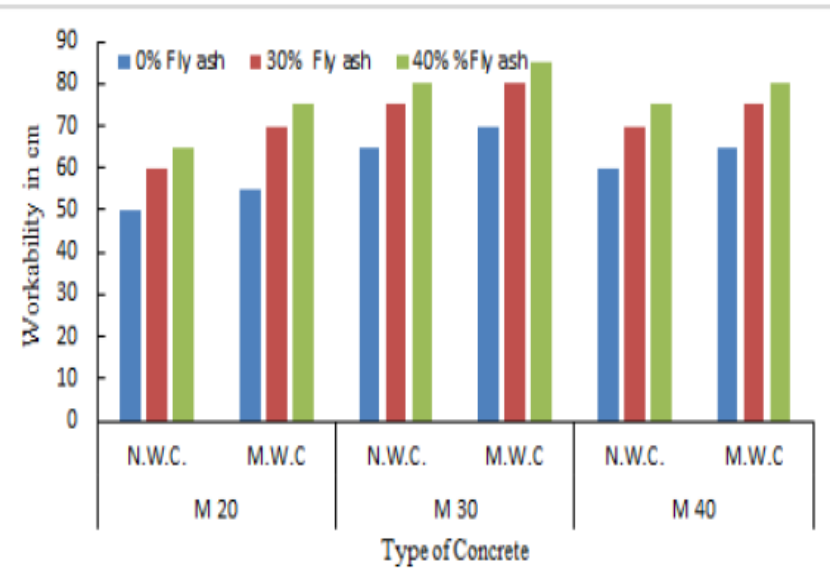

Fig 1: Workability (in $\mathrm{cm}$ ) of N.W.C and M.W.C for different $\%$ fly ash replacements

Table 9 Compressive strengths with different fly ash proportions for M20, M30 and M40

\begin{tabular}{|c|c|c|c|c|c|}
\hline GRADE & DAYS & $0 \%$ Fly ash & $30 \%$ Fly ash & $40 \%$ Fly ash & Target Strength \\
\hline \multirow{4}{*}{ M20 } & 7 & 30.01 & 16.99 & 10.11 & 26.6 \\
\hline & 14 & 38.69 & 25.23 & 16.29 & 26.6 \\
\hline & 21 & 42.47 & 27.86 & 20.47 & 26.6 \\
\hline & 28 & 44.06 & 29.24 & 23.66 & 26.6 \\
\hline \multirow{4}{*}{ M 30} & 7 & 37.77 & 29.43 & 24.65 & 38.25 \\
\hline & 14 & 46.62 & 34.79 & 29.13 & 38.25 \\
\hline & 21 & 51.03 & 37.91 & 33.57 & 38.25 \\
\hline & 28 & 55.899 & 41.34 & 36.46 & 38.25 \\
\hline \multirow{4}{*}{ M 40} & 7 & 43.44 & 30.68 & 29.25 & 48.25 \\
\hline & 14 & 57.93 & 38.26 & 34.4 & 48.25 \\
\hline & 21 & 65.5 & 44.17 & 40.56 & 48.25 \\
\hline & 28 & 72.46 & 51.59 & 46.43 & 48.25 \\
\hline
\end{tabular}




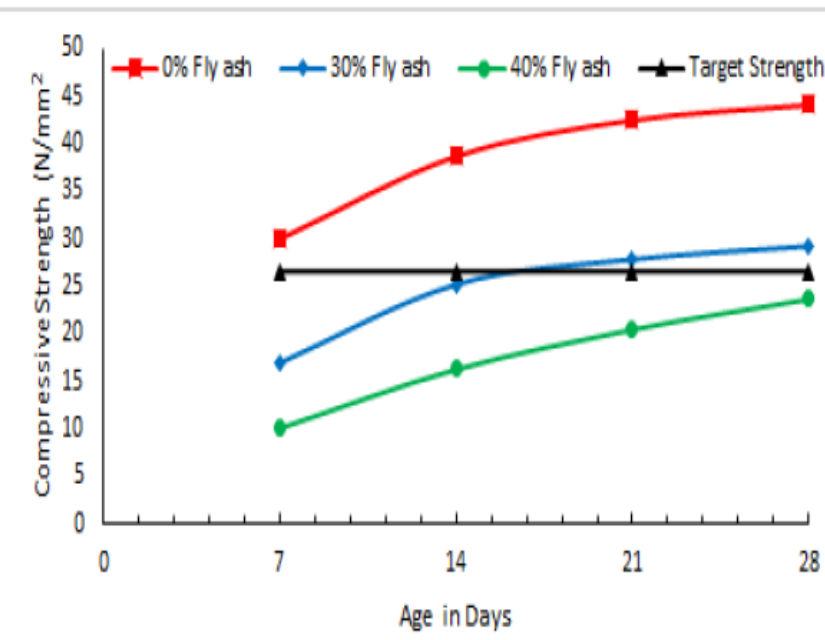

Fig 2: Compressive Strength in NWC and MWC with different fly ash proportions for M20 GRADE

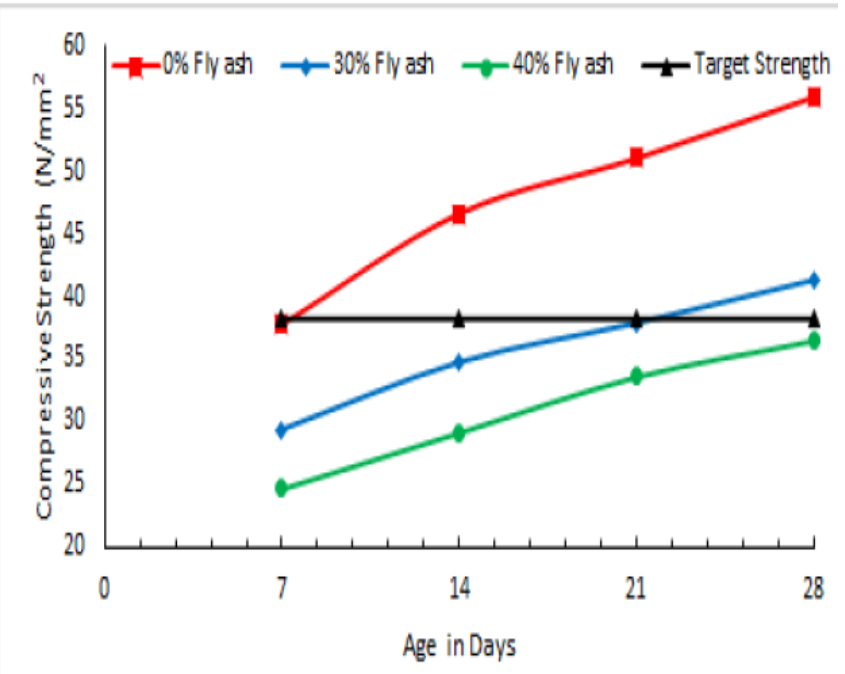

Fig 3: Compressive Strength in NWC and MWC with different fly ash proportions for M30 GRADE

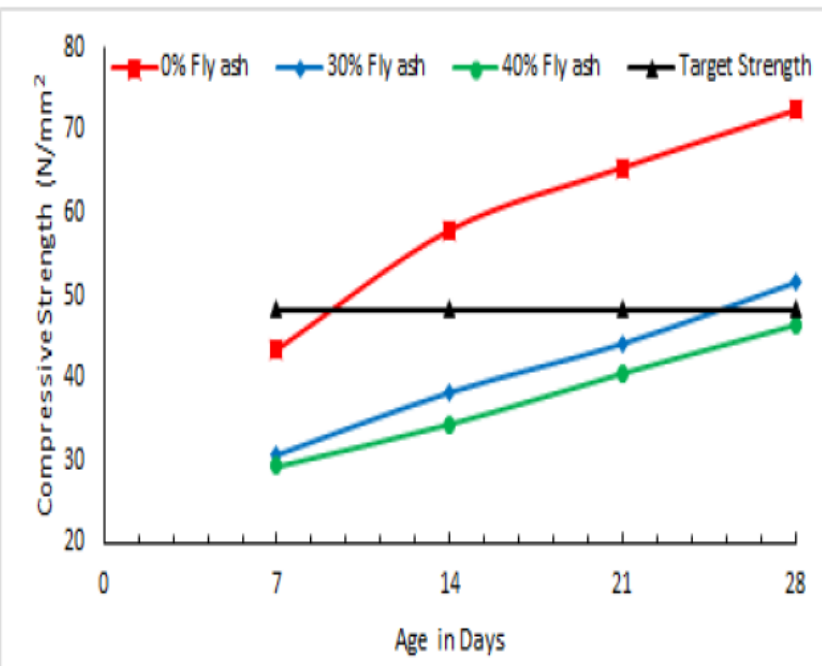

Fig 4: Compressive Strength in NWC and MWC with different fly ash proportions for M40 GRADE

\section{CONCLUSION}

In this experimental work, workability characteristics and compressive strength of concrete made with and without magnetic water are assessed. From the experimental results reported in this paper, the following conclusions are drawn:

1. The workability of fresh concrete is more for MWC than for the conventional NWC and it is also observed that workability increases with the increase of fly ash content in the mix, irrespective of type of water used.

2. When magnetic water is used, the $\%$ increase in the 28 day compressive strengths were found to be $55.7 \%, 43.33 \%$ and $47.04 \%$ for M20, M30 and M40 grades respectively.

3. It is observed that the compressive strengths of M20, M30 \& M40 grade of MWC is comparable to the conventional M35, M45 \& M60 grade of NWC respectively at 28 days.

4. In accordance with the above conclusion, the increase in the compressive strengths observed, can be used to address the need to reduce the cement usage by replacing it with optimum fly ash content. The optimum replacement of cement with fly ash content for M20 grade of concrete at 28 days was observed to be at $34.7 \%$.

5. The optimum replacement of cement with fly ash for M30 \& M40 grades of concrete at 28 days was observed at $36 \% \& 36.5 \%$ respectively.

\section{FUTURE SCOPES}

1. The same investigation of influence of magnetic water on workability and strength properties of concrete can be extended by varying the magnetic strength.

2. Methods can be designed to produce magnetic water on large scale.

3. The present investigation can be extended to make concrete of higher grades and different types of concrete.

\section{REFERENCES}

[1] B.S.K Reddy, Vaishali.G.Ghorpade and H.Sudarsana Rao "Effect of magnetic field exposure time on compressive strength of concrete", International Journal of Advanced Engineering and Technology, Vol. IV/III, P.120122, 2013

[2] B.S.K Reddy et al studied the effect of addition of magnetic water on workability, strength and mechanical properties of concrete, 2014

[3] Maria Eugenia Garcia Harbour., "Changes of biological properties in physical-chemical water induced Magnetic field" Master's thesis submitted at Department of Physical Chemistry, State University of Campinas, Brazil, December 1998, pp.1-112.

[4] Nan Su and Chea-Fang Wu., "Effect of magnetic field treated water on mortar and concrete containing fly ash", Journal of Cement and Concrete Composites, 25, p.269, 2003. 
[5] Nan Su, Yeong-Hwa. Wu and Chung-Yo Mar., "Magnetic water on the engineering properties of concrete containing granulated blast furnace slag", Journal of Cement and Concrete Research, Vol.30, 2000, pp. 599-605.

[6] [S.D.S.Karunanayaka.,"Studies of Magnetic filtration techniques to purify portable water and waste water", Master's Thesis submitted at Institute of information sciences and technology Massey University, palmusrn north, Newzeland.,Sep.2007, pp.1-1. 